\title{
Formulation And Evaluation of Tablets Compressed from Granules Prepared by Thermoplastic Granulation
}

Abstract The aim of this formulation study was to determine the effect of the binder used in the preparation of granules by thermoplastic granulation on the release of propranolol from experimental tablets. Another aim was to select suitable excipients and their ratio in the granules to ensure a trouble-free formulation of the tablets. This study proved that the binder affects the flow properties of the granules, disintegration of the tablets and, subsequently, also the method of drug release, which can be used for the preparation of tablets with modified or prolonged drug release.

Keywords thermoplastic granulation-propranolol dissolution-polyethylene glycol-cetyl stearyl alcohol

\section{INTRODUCTION}

The granulation technique and the binder have an essential influence not only on the granules properties, but also on the properties of the final dosage form. Thermoplastic granulation is a process in which solid particles are converted into agglomerates in the presence of a molten binder. Upon cooling, the binder solidifies again and forms solid bridges between the powder particles. By choosing the right binder material, it is possible to effectively influence the dissolution profile of the final product. When using hydrophilic binders, e.g., polyethylene glycols or poloxamers, a formulation with immediate release is obtained. Instead, lipophilic binders, like waxes, fatty acids or fatty alcohols, are used for manufacturing controlled-release formulations (Keen et al., 2015; Mamidi et al., 2021; Steffens et al., 2020). The aim of this formulation study was to determine the effect of the binder used in the preparation of granules by thermoplastic granulation on the release of propranolol from experimental tablets. Another aim was to select suitable excipients and their ratio in the granules to ensure a trouble-free formulation of the tablets.

\section{MATERIALS AND METHODS}

\section{Chemicals}

Propranolol (Fagron, Olomouc, Czech Republic), polyethylene glycol 1500 (PEG 1500) (Fagron), cetyl stearyl alcohol (CSA)
(Fagron), colloidal silicon dioxide (CSD) (Fagron), lactose (LAC) (Dr. Kulich Pharma, Hradec Králové, Czech Republic), microcrystalline cellulose (MCC) (Centralchem, Bratislava, Slovakia), concentrated hydrochloric acid ( $\mathrm{HCl}$ ) (Centralchem), potassium dihydrogen phosphate $\left(\mathrm{KH}_{2} \mathrm{PO}_{4}\right)$ (Centralchem), stearic acid (Galvex, Banská Bystrica, Slovakia), sodium hydroxide $(\mathrm{NaOH})$ (Mikrochem, Pezinok, Slovakia)

\section{Granule preparation}

Materials sifted through a $1.00-\mathrm{mm}$ sieve were homogenised in a ceramic mortar with a rough base and a ceramic pestle. The granulation mixture was melted for 30 minutes at $80^{\circ} \mathrm{C}$ in a Memmert UNB400 oven (Memmert, Schwabach, Germany). The mixture was stirred every 10 minutes. After cooling, the granulation mixture was extruded through a sieve with a mesh size of $1 \mathrm{~mm}$. CSD and stearic acid were added extragranular to the resulting granules as glidants and antiadhesives. This way, we prepared four types of granules, A3, A4, B3 and B4, with the composition given in Table 1.

\section{Determination of flowability}

Fifty grams of granules was poured loosely into the hopper of Erweka GDT (ERWEKA GmbH, Heusenstamm, Germany). After start-up, the instrument recorded the time it took for 
Table 1. Composition of granules in percentages by weight.

\begin{tabular}{|c|c|c|c|c|}
\hline & $\begin{array}{c}\text { A3 } \\
(\%)\end{array}$ & $\begin{array}{c}\text { A4 } \\
(\%)\end{array}$ & $\begin{array}{c}\text { B3 } \\
(\%)\end{array}$ & $\begin{array}{c}\text { B4 } \\
(\%)\end{array}$ \\
\hline LAC & 33 & 28 & 33 & 28 \\
\hline MCC & 33 & 28 & 33 & 28 \\
\hline PEG 1500 & 28 & 38 & - & - \\
\hline CSA & - & - & 28 & 38 \\
\hline Stearic acid & 1.5 & 1.5 & 1.5 & 1.5 \\
\hline CSD & 1.5 & 1.5 & 1.5 & 1.5 \\
\hline Propranolol & 3 & 3 & 3 & 3 \\
\hline
\end{tabular}

the sample to flow. The measurement was repeated 3 times for each sample.

\section{Determination angle of repose}

Fifty grams of granules was poured continuously onto the inside of the funnel, which was placed $4 \mathrm{~cm}$ above the presumed top of the cone. The granules was allowed to flow freely on a solid base. The height $(h)$ and the radius $(r)$ of the resulting cone were measured and the angle of repose was calculated using Equation 1. The test was repeated 3 times for each sample.

$$
\alpha=\operatorname{arctg} \frac{h}{r}\left[{ }^{\circ}\right]
$$

\section{Carr compressibility index and Hausner ratio}

One hundred millilitres $\left(\mathrm{V}_{0}\right)$ of granules was poured freely into the measuring cylinder and its weight was measured. Subsequently, 10, 50 and 100 taps on the solid surface were performed, after which the compacted volume $\left(V_{f}\right)$ was recorded. Based on the values $V_{0}$ and $V_{f}$ after 100 taps, the compressibility index was calculated using Equation 2 and the Hausner ratio was calculated using Equation 3. The test was repeated 3 times with each sample.

Carr compressibility index $=100 \frac{v_{0}-v_{f}}{v_{0}}$

Hausner ratio $=\frac{V_{0}}{V_{100}}$

\section{Tablet preparation}

Tablets were compressed on a Romaco AM 8 rotary press (Romaco, Milan, Italy). The compression pressure was approximately $85 \mathrm{MPa}$ for all granules. The height of the upper die was set to $15 \mathrm{~mm}$.

\section{Weight uniformity of tablets}

Weight uniformity of the prepared tablets was performed according to the European Pharmacopoeia 10.5 (European Pharmacopoeia, 2010).

\section{Tablet disintegration}

Tablet disintegration was evaluated using Erweka ZT3-2 (ERWEKA GmbH). One tablet was placed in each of the six tubes of the device and the medium was placed in a beaker. Also, $0.1 \mathrm{~mol} / \mathrm{l} \mathrm{HCl}$ and phosphate buffer with $\mathrm{pH} 6.8$ were used as media. The whole system was tempered to $37^{\circ} \mathrm{C}$. In both media, the test was run for 60 minutes at a frequency of vertical movement of the hanging device with 30 oscillations per minute.

\section{Basket tablet dissolution}

A Hanson SR8 PLUS dissolution device (Teledyne Hanson Research, Chatsworth, CA, USA) was used to dissolve the tablets. The device consists of eight containers and baskets. Seven propranolol tablets were placed in the baskets, one on each basket. A tablet with the same excipients but without the drug was placed in the last one. The distance between the basket and the inner bottom of the container was $25 \mathrm{~mm}$. The baskets with the tablet rotated about their own axis at a speed of 50 turns per minute. The whole system was tempered to 37 ${ }^{\circ} \mathrm{C}$. At intervals of $5,10,15,22,30,42,5565,70,75,82,105,120$, $180,240,300,360,540,720$ and 1440 minutes, 2 ml of solution was collected from each of the eight vessels using a syringe with a needle into the prepared microtubes. The missing 2 $\mathrm{ml}$ of solution was replaced with pure dissolution liquid. The dissolution medium consisted of $750 \mathrm{ml}$ of $0.1 \mathrm{~mol} / \mathrm{l} \mathrm{HCl}$, to which a mixture of $46 \mathrm{ml}$ of $0.2 \mathrm{~mol} / \mathrm{l} \mathrm{NaOH}, 200 \mathrm{ml}$ of $0.2 \mathrm{~mol} / \mathrm{I}$ $\mathrm{KH}_{2} \mathrm{PO}_{4}$ and $4 \mathrm{ml} \mathrm{H}_{2} \mathrm{O}$ was added after 60 minutes of dissolution. The amount of propranolol in the samples was determined spectrophotometrically at a wavelength of $290 \mathrm{~nm}$ with the spectrophotometer Cary 60 (Agilent technologies, Santa Clara, CA, USA). Korsmeyer-Peppas dissolution model was used to describe the release kinetics from the tablets.

\section{RESULTS AND DISCUSSION}

In this formulation study, four types of granules were prepared by thermoplastic granulation. Granules A3 and A4 contained PEG 1500 and granules B3 and B4 contained CSA as the binder. PEGs are stable hydrophilic substances that are widely used in different types of pharmaceutical formulations, including parenteral, topical, ophthalmic, oral and rectal dosage forms. In solid drug formulations, PEGs with high molecular weight are used as binders in granulation to provide strength and plasticity to the granules. At high concentrations, they have the ability to prolong disintegration, which can be used to prepare dosage forms with delayed disintegration time. On the other hand, CSA is a lipophilic mixture of solid aliphatic alcohols consisting mainly of stearyl alcohols and cetyl alcohols. CSA is used mainly in cosmetics and topical pharmaceuticals. In addition, CSA can be used to control or slow the dissolution rate of tablets containing well or sparingly water-soluble drugs (Rowe et al., 2009). 


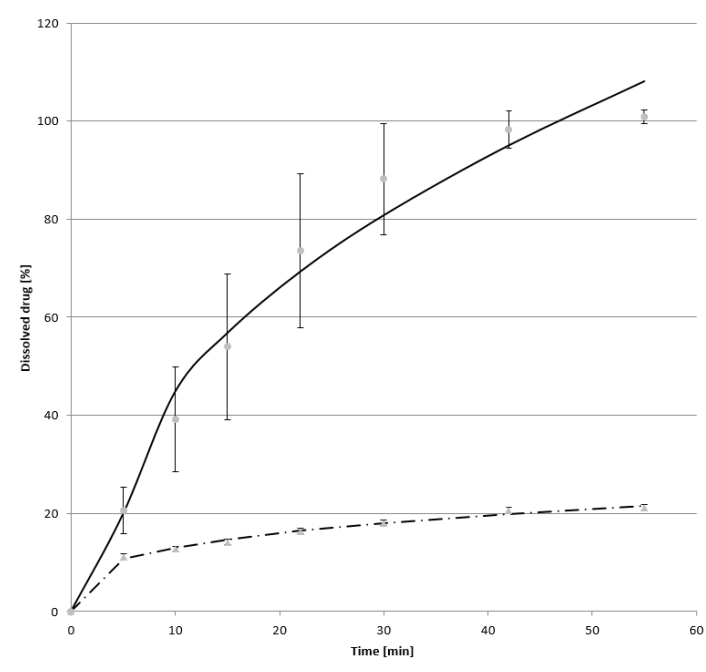

Figure 1. Dissolution profile of tablets $A 3, B 3$ in the acidic medium.

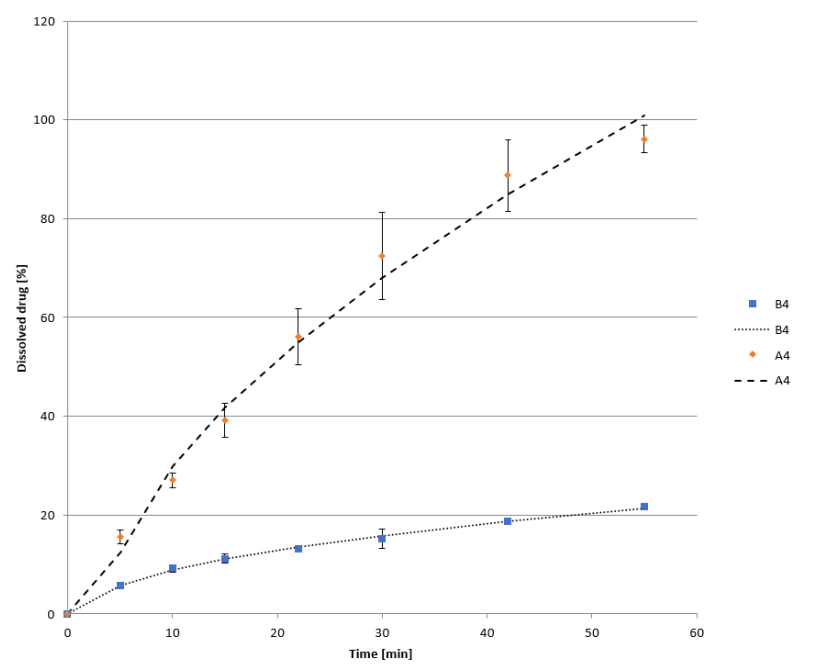

Figure 2. Dissolution profile of tablets $A 4, B 4$ in the acidic medium.

The prerequisites for tablet compression without technological problems are good flow properties of the powders or granules. Therefore, in this study, extragranular excipients were added to the base granules. CSD, which is widely used in the manufacture of powders, capsules and tablets, has been used as a lubricant; while it improves the flow properties of powders, it also has a beneficial effect on the mechanical properties and disintegration of tablets. Stearic acid was used to prevent the tablet from sticking to the dies (Jonat et al., 2006, Komárek et al., 2006). After addition of extragranular excipients, the flowability of samples A3, A4, B3 and B4 was $6.60 \pm 0.00,15.73 \pm 0.3,6.93 \pm$ 0.23 and $15.47 \pm 0.42$ seconds. It follows that the flowability was affected by the amount of binder and not its character. Angle of repose of samples A3, A4, B3 was $34.14^{\circ} \pm 0.04^{\circ}$,

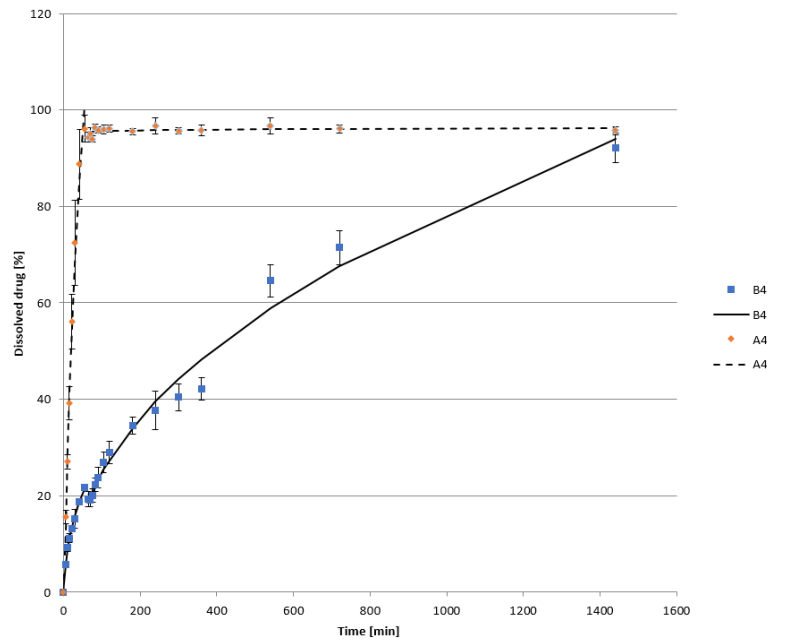

Figure 3. Dissolution profile of tablets $A 3, B 3$ during the whole time dissolution.

$34.81^{\circ} \pm 0.00^{\circ}, 35.09^{\circ} \pm 0.05^{\circ}$, which represents good flow properties of the granules. For sample B4 with the angle of repose $36.57^{\circ} \pm 0.01^{\circ}$, the flow property was adequate. The Carr compressibility index of samples A3, A4, B3 and B4 was $9 \%, 10 \%, 15 \%$ and $11 \%$ and the Hausner ratio was $1.10,1.11$, 1.18 and 1.12. These values show that the flow character was excellent in samples $A 3$ and $A 4$, good in sample B3 and adequate in sample B4.

The preparation of tablets from these granules did not cause technological problems, the dies were filled sufficiently, and there was no sticking of the tablets to the walls of the die and the surface of the dies. At the same press setting, the average weight of the tablets was A3, A4, B3, B4, 567, 534, 628 and $629 \mathrm{mg}$. Each batch of tablets passed the weight uniformity test, where the average deviation for all types of tablets was between $1 \%$ and $2 \%$. In the disintegration test, tablets A3, A4 and $\mathrm{B} 3$ disintegrated completely in $\mathrm{HCl}$ as well as in buffer within 60 minutes. B4 tablets retained their shape in both liquids throughout the test.

Dissolution profiles clearly showed that the drug was released significantly faster from tablets $A 3$ and $A 4$, for which the release half-life was calculated to be $12.56 \pm 6.10$ and $19.10 \pm 2.31$ minutes. The faster drug release was due to the hydrophilic properties of PEG. In the aqueous solution, water was transferred to PEG, which led to disintegration of the tablets. In contrast, the release half-life of propranolol for tablets B3 and B4 was $186.17 \pm 9.90$ and $332.44 \pm 27.47$ minutes. Due to the lipophilicity of CSA, the drug was released gradually because the dissolution fluid transfer was not accelerated by the hydrophilicity of the binder. The difference in the release rate of propranolol depending on the binder is clearly seen on the dissolution curves in acidic $\mathrm{HCl}$ medium (Figs 1 and 2) and during the whole dissolution time (60 minutes $\mathrm{HCl}+$ remaining time in phosphate buffer with $\mathrm{pH} 6.8$ ) as shown in the graphs in Figs 3 and 4. 


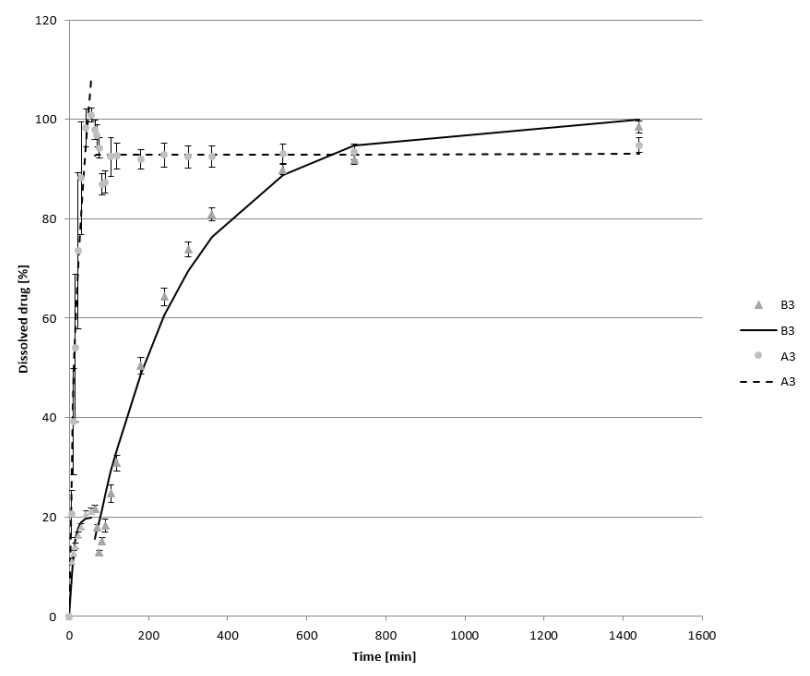

Figure 4. Dissolution profile of tablets A4, B4 during the whole time dissolution.

The effect of binder concentration on the release of propranolol from tablets was evaluated using a difference factor $\left(f_{1}\right)$ and a similarity factor $\left(f_{2}\right)$. The difference factor $\left(f_{1}\right)$ measures the percent error between two curves over all time points. The percent error is zero when the test and drug reference profiles are identical and increases proportionally with the dissimilarity between the two dissolution profiles. The similarity factor is a logarithmic transformation of the sum-squared error of differences between the test and reference samples over all time points. The $\mathrm{f}_{2}$ can take values between 0 and 100. A value of 100 means that the dissolution profiles are identical and a value of 0 indicates a complete mismatch in the dissolution profiles. The similarity factor and the difference factor were adopted by the Food and Drug Administration (FDA) and the European Medicines Agency (EMA) as a criterion for assessing the similarity between two in vitro dissolution profiles. The FDA and the EMA consider the dissolution profiles to be similar if $\mathrm{f}_{1}$ is less than 15 and $\mathrm{f}_{2}$ is greater than 50 (Costa and Sousa Lobo, 2001). When comparing samples A4 (reference sample) and A3 (test sample), the value of $f_{1}$ was $7.77 \pm 2.66$ and $f_{2}$ was $54.47 \pm$ 9.89. It follows that the drug release from these samples is similar. From this, it can be concluded that the concentration of PEG 1500 did not have a significant effect on the release of propranolol from the experimental tablets. When comparing the dissolution profiles of tablets B3 (test sample) and B4 (reference sample), the values of $f_{1}$ and $f_{2}$ were $26.87 \pm 1.64$ and $41.18 \pm 1.65$, which differs slightly from the values at which it can be argued that the dissolution profiles are similar. Based on these values, it can be concluded that the concentration of CSA slightly affects the release of propranolol from the experimental tablets.

This formulation study has shown that the character and concentration of the binder affects the properties of the granules and tablets. The binder affects the flow properties of granules, disintegration of the tablets and, subsequently, also the method of drug release, which can be used for the preparation of tablets with modified or prolonged drug release.

\section{ACKNOWLEDGMENT}

The work was designed thanks to the support provided by the project from the structural fund, "Renewal of research and development infrastructure and instrumentation at UVLF, ITMS 26210120028."

\section{References}

[1] Costa P, Sousa Lobo JM. Modeling and comparison of dissolution profiles. Vol. 13, European Journal of Pharmaceutical Sciences. Elsevier; 2001. p. 123-33.

[2] European Pharmacopoeia. Uniformity of mass of single-dose preparations. Eur Pharmacopoeia. 2010;(1):291-2.

[3] Jonat S, Albers P, Gray A, Schmidt PC. Investigation of the glidant properties of compacted colloidal silicon dioxide by angle of repose and X-ray photoelectron spectroscopy. Eur J Pharm Biopharm. 2006;63(3):356-9.

[4] Keen JM, Foley CJ, Hughey JR, Bennett RC, Jannin V, Rosiaux Y, et al. Continuous twin screw melt granulation of glyceryl behenate: Development of controlled release tramadol hydrochloride tablets for improved safety. Int J Pharm [Internet]. Elsevier B.V.; 2015;487(1-2):72-80. Available from: http://dx.doi.org/10.1016/j. ijpharm.2015.03.058

[5] Komárek P, Rabišková $M$, Chalabala $M$, Kopecký $F$, Vitková $M$, Řehula M, et al. Technologie léku. Praha: Galén; 2006.
[6] Mamidi HK, Palekar S, Nukala PK, Mishra SM, Patki M, Fu Y, et al. Process optimization of twin-screw melt granulation of fenofibrate using design of experiment (DoE). Int J Pharm [Internet]. Elsevier B.V.; 2021;593(September 2020):120101. Available from: https://doi.org/10.1016/j.ijpharm.2020.120101

[7] Rowe RC, Sheskey PJ, and Owen SC. Handbook of pharmaceutical excipients. London: Pharmaceutical Press; 2006.

[8] Steffens KE, Brenner MB, Hartig MU, Monschke M, Wagner KG. Melt granulation: A comparison of granules produced via highshear mixing and twin-screw granulation. Int J Pharm [Internet]. Elsevier B.V.; 2020;591(March):119941. Available from: https:// doi.org/10.1016/j.ijpharm.2020.119941 